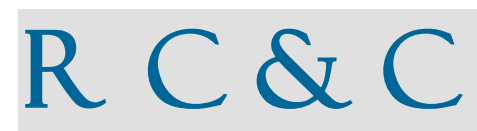

\title{
GESTÃO DOS DIREITOS ECONÔMICOS DE ATLETAS PROFISSIONAIS NO FUTEBOL BRASILEIRO E CAPTAÇÃO DE RECURSOS NO MERCADO DE AÇÕES: RELATO DE UMA ESTRATÉGIA.
}

\section{MANAGEMENT OF ECONOMIC RIGHTS OF PROFESSIONAL ATHLETES IN BRAZILIAN FOOTBALL AND FUNDRAISING IN THE STOCK MARKET: REPORT OF A STRATEGY.}

Recebido em 11.04.2014 | Aceite final em 25.11.2014 |

Nota: este artigo foi aceito pelo Editor Jorge Eduardo Scarpin e passou por uma avaliação double blind review A reprodução dos artigos, total ou parcial, pode ser feita desde que citada a fonte.

ODIRLEI ACIR TEDESCO Mestre em Contabilidade | Universidade Federal do Paraná | Avenida Prefeito Lothário Meissner 632 | 1ㅇ Andar | Campus III | Jardim Botânico | Curitiba- PR | Brasil | CEP 80210-170 | Telefone (+5541) 3360-4404 | E-mail: odirleitedesco@hotmail.com |

LAURO BRITO DE ALMEIDA Doutor e Mestre em Controladoria e Contabilidade | Universidade de São Paulo| Professor do Programa de Pós-Graduação em Contabilidade | Universidade Federal do Paraná |Avenida Prefeito Lothário Meissner 632 | 10 Andar | Campus III | Jardim Botânico | Curitiba- PR | Brasil | CEP 80210-170 | Telefone (+5541) 3360444 |E-mail: gbrito@uol.com.br |

VICENTE PACHECO Doutor em Engenharia de Produção | Universidade Federal de Santa Catarina | Professor do Programa de Pós-Graduação em Contabilidade I Universidade Federal do Paraná | Avenida Prefeito Lothário Meissner 632 | 10 Andar | Campus III | Jardim Botânico | Curitiba-PR | Brasil | CEP 80210-170 | Telefone (+5541) 33604444 | E-mail: vpacheco@ufpr.br |

CHRISTIAN LUIZ DA SILVA Pós-Doutor Administração | Universidade de São Paulo |Doutor em Engenharia de Produção | Universidade Federal de Santa Catarina | Professor do Departamento de Gestão e Economia | Universidade Tecnológica Federal do Paraná | Programa de Pós-graduação em Planejamento e Governança Pública | Mestrado profissional | Universidade Tecnológica Federal do Paraná | Campus Curitiba | Avenida Sete de Setembro 3165 | Centro | Curitiba-PR | Brasil | CEP 80230-901 |Telefone (+5541) 3310-4611 |E-mail: christiansilva@utfpr.edu.br | 


\section{RESUMO}

O futebol, na maneira como hoje o conhecemos, é praticado desde 1863, tendo sua origem na Inglaterra. Desde então, vem crescendo e se popularizando, resultando numa movimentação financeira cada vez maior. No mundo são movimentados bilhões de dólares na venda de direitos de transmissão pela televisão, negociação de atletas, marketing desportivo, dentre outras fontes. Principalmente no continente europeu, o futebol adentrou ao mercado acionário por meio da abertura de capital de clubes como Manchester United PLC, AS Roma SpA, SL Benfica SAD, dentre outros. A alternativa de captação de recursos no mercado ações não pôde ser adotada no Brasil, onde a abertura de capital, regulamentada por legislação específica e controlada pela Comissão de Valores Mobiliários (CVM), não prevê a possibilidade de abertura de capital em clubes de futebol, constituídos sob a forma de associação civil sem fins lucrativos. Entretanto, o Paraná Clube, de forma inédita, efetuou a integralização de direitos econômicos decorrentes de contratos com jogadores profissionais de futebol numa sociedade anônima de capital aberto, tornando-se seu acionista majoritário controlador. Pode-se afirmar que houve a abertura indireta de capital no segmento desportivo. Neste contexto, o presente estudo questiona: Como deve ser estruturada a estratégia, por um clube de futebol profissional, para a gestão do ativo direito econômico de atletas profissionais e captação de recursos no mercado acionário brasileiro? Para responder, foi adotada como metodologia o Estudo de Caso que, por meio de entrevistas e pesquisa bibliográfica com análise de conteúdo, foi possível a descrição e análise do inédito caso, resultando numa coletânea de procedimentos e etapas do processo. Os resultados obtidos demonstraram a estratégia de um clube de futebol brasileiro para, de forma indireta, colocar no mercado de ações os ativos originados de contratos mantidos com atletas profissionais de futebol e, assim, abrir a possibilidade de captação de recursos a custo razoável.

Palavras-Chave: Futebol. Abertura de Capital. Paraná Clube.

\section{ABSTRACT}

The football the way we know it is practiced since 1863, having its origin in England. Since then has been growing and becoming more popular, resulting in an increasing financial transactions. In the world are moved billions of dollars in the sale of television broadcast rights, negotiation of athletes, sports marketing, among other sources. Mainly in Europe, football entered the stock market through the Initial Public Offering (IPO), of clubs like Manchester United PLC, AS Roma SpA, SL Benfica SAD, among others. The alternative fundraising market shares could not be adopted in Brazil, where the IPO, regulated and controlled by Securities and Exchange Commission of Brazil specific legislation does not provide for the possibility of IPO in football clubs, made in the form of association civil nonprofit. However Paraná Clube, in an unprecedented way, made the payment of economic rights arising from contracts with professional football players in 


\begin{abstract}
a publicly traded corporation, becoming its majority shareholder controller. It can be stated that there was indirect IPO in the sports segment. In this context, this study asks: How should it be structured strategy for a professional football club, for the management of active economic rights of professional athletes and fundraising in the Brazilian stock market? To answer, was adopted as the methodology Case Study where, through interviews and literature with content analysis was possible the description and analysis of the original case, resulting in a collection of procedures and process steps. The results showed the strategy of a Brazilian football club, indirectly, put in the stock market the assets originating from contracts held with professional soccer players, and thus open the possibility of raising funds at a reasonable cost.
\end{abstract}

Key-words: Football. IPO. Paraná Clube.

\section{INTRODUÇÃO}

A história contemporânea de um dos esportes mais populares do mundo, o futebol, se estende por mais de um século e meio. Em 1863, na Inglaterra, com o rugby e o futebol assumindo formatos diferentes, ocorreu a formalização da prática do futebol, enquanto atividade esportiva, com a fundação da Associação de Futebol da Inglaterra, primeiro órgão oficial do esporte constituído no mundo (FIFA, 2013).

O futebol, para muitos é paixão nacional. No Brasil, o futebol além de paixão, é uma marca registrada, utilizada como estratégia de marketing por onde quer que passe. O futebol tem o condão de congregar multidões e gerações em torno de um clube e, neste contexto, promove a integração social e cultural. Também, tem papel no processo educacional - às vezes - como instrumento auxiliar na política de saúde, posto que sua prática, ainda que seja como lazer, é uma atividade física benéfica. Estes fatores justificam a atenção do governo ao esporte - em geral e, especificamente, ao futebol - ao estabelecer marcos regulatórios (MELO FILHO, 2001).

A introdução da prática do futebol no Brasil é creditada a Charles Miller - pai inglês e mãe brasileira que em 1894 retornando a São Paulo após um período de estudos em Southhampton na Inglaterra, trouxe bola e uniformes. Foi o organizador dos primeiros jogos de futebol, com equipes formadas funcionários brasileiros e ingleses da Companhia do Gás, do London Bank e da São Paulo Railway. Em geral, a mídia esportiva promove o Brasil como "o país do futebol", porém, o paradoxo é que no início, a prática do futebol era prerrogativa dos ricos e aristocratas. Não demorou muito para o futebol ser praticado pelos demais extratos da camada social (LOPES, 1994, p. 69 e 80). Porém, em muitos clubes de futebol - em especial os da elite - a admissão de atletas profissionais negros foi mais lenta, e por vezes dolorosa.

A gestão dos clubes de futebol profissional, em sua fase inicial, foi marcada por uma atuação amadora. Nesse ambiente, o foco da gestão dos clubes ou times de futebol era apenas nos resultados desportivos, movidos pela paixão de dirigentes e jogadores. Os dirigentes e jogadores atuavam desvinculados de preocupações financeiras ou de gestão. Neste estágio inicial, na estrutura organizacional, de certa forma, havia um nivelamento nas estruturas administrativas e financeiras dos clubes de futebol.

Passada a fase inicial de "amor à camisa", o futebol enquanto negócio no Brasil e no mundo, movimenta um volume de recursos financeiros, que ao longo dos tempos passou a ser extremamente representativo na economia e para a geração de recursos aos clubes. As frequentes 
transações entre atletas e clubes movimentam montantes expressivos de recursos que facilmente atingem cifras de bilhões de dólares, estando inclusos, além dos direitos econômicos dos atletas, a comercialização dos direitos de transmissão dos torneios, a venda de materiais esportivos, a venda de espaços para anúncios em estádios e em uniformes, dentre outros (BOENTE; DANTAS, 2011).

Os clubes de futebol profissional, em geral, optam por serem estruturados juridicamente como organizações sem fins lucrativos. A opção por esse arranjo juridico, ainda que previsto no marco legal, traz vantagens e desvantagens. Entre as desvantagens, a perpetuação da ficção de ente "sem fins lucrativo" - que abre as portas para reclamar e obter toda sorte de benefícios - e a não permissão de acesso ao mercado acionário, ao contrário dos clubes europeus.

As fontes de receitas dos clubes profissionais de futebol são variadas, no Brasil e no mundo. Em específico no caso brasileiro, o levantamento da BDO RCS (2012) evidencia uma participação crescente das receitas de direitos de transmissão, cujos contratos são firmados com as emissoras de televisão (TV) e a redução de receitas oriundas da negociação de direitos econômicos dos atletas profissionais.

Os direitos econômicos originados de contratos firmados com atletas profissionais de futebol são ativos relevantes para os clubes de futebol profissional. Dadas as características deste tipo de ativo, por força das normativas contábeis devem ser contabilizados como Ativo Intangível, sujeitos às regras de avaliação e de amortização aplicáveis. Infelizmente, em decorrência do marco legal, os clubes de futebol profissional no Brasil, ainda que estejam organizados como empresas e mesmo que todos o fossem, estão impedidos de abrirem seu capital (Initial Public Offering -IPO), e negociarem ações na Bolsa de Valores.

Portanto, nesse contexto, a questão de pesquisa que se coloca é:"Como deve ser estruturada a estratégia, por um clube de futebol profissional, para a gestão do ativo direito econômico de atletas profissionais e captação de recursos no mercado acionário brasileiro?". Além desta introdução, o texto está organizado em mais quatro seções: 2. Marco Teórico-Empírico; 3. Metodologia; 4. Resultados e Discussão; e 5. Considerações Finais.

\section{MARCO TEÓRICO-EMPÍRICO}

\subsection{EVOLUÇ̃̃O DO MARCO REGULATÓRIO DOS ClUBES DE FUTEBOL PROFISSIONAL NO BRASIL}

O marco regulatório do esporte brasileiro, em específico do futebol, vem sendo construído ao longo das últimas décadas. Anterior a 1993, quando foi promulgada a Lei no 8.672 de 06/07/1993 (Lei Zico), a legislação desportiva era predominantemente genérica, não promovendo e tampouco proporcionando as bases para a profissionalização do negócio futebol e demais modalidades desportivas. A Lei no 9.615 de 24/03/1998, atualmente em vigor, também conhecida como Lei Pelé, trouxe, ao cenário desportivo, significativas modificações, com grande impacto nas relações contratuais e econômicas para os clubes, atletas profissionais e outros agentes interessados.

A análise comparativa feita por Tubino (2002) das Leis Zico e Lei Pelé, mostrou não existirem diferenças significativas entre elas, especialmente na regulamentação dos conceitos, princípios e definições de referência. Por outro lado, a Lei Pelé foi muito mais impactante sobre o ordenamento jurídico do futebol brasileiro, determinando a extinção do "passe" dos atletas e, com isso, abrindo espaço e oportunidade para o desenho de um novo modelo de relacionamento entre os atletas profissionais de futebol e os clubes de futebol profissional.

No Quadro 1, estão listada as principais leis sobre o desporto no Brasil. Anterior a 1941, abrangendo o período do Brasil colônia até o Estado Novo, a regulamentação desportiva, insipiente, tratava basicamente dos esportes no âmbito das escolas militares (TUBINO, 2002). 
Quadro 1: Evolução das Principais Normas Aplicáveis ao Desporto.

\begin{tabular}{|c|c|}
\hline DIPLOMA LEGAL & PONTOS PRINCIPAIS \\
\hline $\begin{array}{l}\text { Decreto-Lei no } \\
\text { 3.199 de } \\
\text { 14/04/1941 }\end{array}$ & $\begin{array}{l}\text { No Governo de Getúlio Vargas teve início a regulamentação do desporto no Brasil. Este } \\
\text { decreto estabeleceu normas gerais estruturando o desporto brasileiro, criando o } \\
\text { Conselho Nacional do Desporto, as Federações e Confederações. Parcialmente em vigor. }\end{array}$ \\
\hline $\begin{array}{l}\text { Lei } n=8.672 \text { de } \\
06 / 07 / 1993 .\end{array}$ & $\begin{array}{l}\text { A chamada "Lei Zico" trouxe ordenamento mais específico para o desporto brasileiro, } \\
\text { incluindo o futebol. Possuía vários dispositivos de cunho sugestivo, principalmente } \\
\text { quanto à profissionalização do futebol e à fiscalização dos clubes. Foi revogada pela "Lei } \\
\text { Pelé". }\end{array}$ \\
\hline $\begin{array}{l}\text { Lei no } 9.615 \text { de } \\
\text { 24/03/1998. }\end{array}$ & $\begin{array}{l}\text { A "Lei Pelé" constituiu-se no novo marco legal brasileiro no desporto, trazendo vários } \\
\text { aperfeiçoamentos no ordenamento. Nesta lei foi extinto o "passe" no futebol brasileiro, } \\
\text { sendo celebrada como a lei de liberdade dos atletas. }\end{array}$ \\
\hline $\begin{array}{c}\text { Lei } n=12.395 \text { de } \\
16 / 03 / 2011\end{array}$ & $\begin{array}{l}\text { Aperfeiçoamento da "Lei Pelé", trazendo várias alterações nos dispositivos anteriores, } \\
\text { notadamente quanto às cláusulas indenizatória desportiva e compensatória desportiva. }\end{array}$ \\
\hline
\end{tabular}

Fonte: Elaborado pelos autores (2013)

A relação entre capital e trabalho sempre foi permeada por certo grau de tensão social e assimetria de informação. Na legislação desportiva vigente, os mecanismos de garantias asseguram aos atletas profissionais que clubes contratantes cumpram as obrigações trabalhistas. Nas relações contratuais no futebol profissional brasileiro, a lei inova ao assegurar o direito de, ao término de seu contrato de trabalho, o atleta profissional se transferir para qualquer outra entidade esportiva. Essa inovação somente foi possível com a extinção da prática e figura do "passe" no Brasil.

Com a edição da Lei Pelé (BRASIL, 1998) e extinção do "passe" no futebol brasileiro, novas abordagens nas relações contratuais entre atleta profissional e clube surgiram, como parte de um processo de evolução, principalmente, inovando com a criação dos Direitos Federativos e Direitos Econômicos no meio desportivo. O diagrama na Figura 1 detalha a natureza e características dos Direitos Federativos e Econômicos.

DIREITOS DECORRENTES DO CONTRATO DESPORTIVO (VISÃO dOS DIREITOS A SEREM EXERCIDOS PELO CLUBE DE FUTEBOL)

\section{DIREITOS FEDERATIVOS}

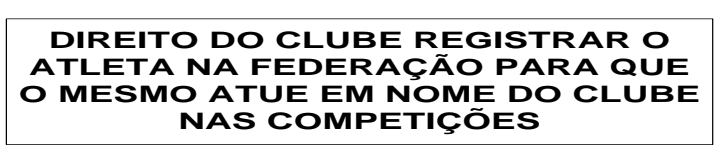

SOMENTE UM DETENTOR: NÃO PODE SER DIVIDIDO.

\section{DIREITOS ECONÔMICOS}

COMPENSAÇÃO FINANCEIRA QUE O CLUBE RECEBE POR TRANSFERIR OS DIREITOS FEDERATIVOS A OUTRO CLUBE

PODE SER NEGOCIADO E DIVIDIDO LIVREMENTE (FRACIONADO)

VALOR PARA TRANSFERÊNCIAS NACIONAIS:

- LiVREMENTE PACTUADO, TENDO COMO LIMITE 2.000 VEZES O SALÁRIO CONTRATUAL.

VALOR PARA TRANSFERÊNCIAS INTERNACIONAIS:

$\Rightarrow$ LiVREMENTE PACTUADO, SEM LIMITES.

Figura 1: Direitos Decorrentes do Contrato Desportivo. Fonte: Elaborado pelo autor com base na Lei no 9.615/1998. 


\section{DiREITOS FEDERATIVOS}

Os clubes de futebol profissional têm determinadas características que os diferenciam de outras organizações. Para os clubes, um atleta é um valioso ativo, que em função de seu talento, de sua habilidade e etc., ou seja, do potencial de benefícios futuros, origina um ativo intangível. A contratação de atletas ocorre por duas vias: (i) contratando atletas profissionais junto a outros clubes de futebol profissional ou (ii) pactuando o primeiro contrato com atletas formados nas chamadas "categorias de base".

Como regra geral, os contratos de trabalho do atleta profissional deverão ser pactuados por prazo determinado, nunca inferior a três meses nem superior a cinco anos. Um caso particular nessa regra geral é o primeiro contrato especial de trabalho esportivo firmado com atletas com idade mínima de 16 anos, formados em suas "categorias de base". Nesse caso, o clube formador tem assegurado por lei o direito de firmar o primeiro contrato especial de trabalho desportivo com o atleta e, também, o direito de preferência para a primeira renovação. O prazo contratual de renovação do contrato não poderá exceder a 3 (três) anos, salvo para equiparação de proposta de outro clube.

Com a nova redação dada ao artigo 5 o da Lei Pelé (1998), pela Lei no 12.395/2011, o vínculo desportivo do atleta com a entidade desportiva contratante é legalmente formalizado com o registro do contrato especial de trabalho desportivo na entidade de administração do desporto. Assim, o Direito Federativo estará assegurado ao clube de futebol profissional.

Nos termos da lei vigente, para o atleta exercer sua atividade no futebol profissional, é necessário atender, concomitantemente, a dois requisitos: (i) estar, por meio de contrato, vinculado a um clube de futebol profissional e (ii) o clube, de posse do contrato, registrá-lo na respectiva federação. Atendidos esses requisitos, o clube de futebol profissional poderá utilizar o atleta em torneios e se beneficiar de sua técnica e esforço. No entanto, o marco legal não permite o compartilhamento concomitante dos serviços dos atletas entre entidades desportivas.

O Direito Federativo assegura ao clube o direito de registrá-lo na entidade gestora da atividade esportiva e seu período de vigência (início e fim) é o mesmo pactuado no Contrato de Trabalho entre o jogador de futebol e o clube. A extinção do Direito Federativo ocorre na data acordada para término do contrato especial de trabalho desportivo, ou qualquer outra data em caso de rescisão antecipada.

Por outro lado, nesse contexto de relações contratuais, a natureza acessória ao respectivo vínculo empregatício prevê dissolução do contrato nas seguintes condições: (i) com o término da vigência do contrato ou o seu distrato; (ii) com o pagamento da cláusula indenizatória desportiva ou da cláusula compensatória desportiva; (iii) com a rescisão decorrente do inadimplemento salarial, de responsabilidade da entidade de prática desportiva empregadora; (iv) com a rescisão indireta, nas demais hipóteses previstas na legislação trabalhista; e (v) com a dispensa imotivada do atleta.

\section{DIREITOS ECONÔMICOS}

O atleta profissional de futebol, enquanto ativo econômico, esteve até a edição da Lei Pelé, vinculado ao clube por meio da figura do "passe". Conforme a Lei no 6.354/1976, o "passe" - além de assegurar o direito sobre o atleta - era expresso por um valor monetário, devido por um clube empregador a outro, pela cessão do atleta durante a vigência do contrato ou após seu término. Sobre esse mecanismo, com respaldo na legislação vigente na época, GUERRA (2003) argumenta que os clubes de futebol profissional faziam do passe verdadeiro capital ativo, fonte principal de renda e subsistência. Esse tipo de negócio era possível porque o "passe" impedia que o atleta ao término de seu contrato se transferisse para outro clube, enquanto não fosse pago ao último empregador o montante monetário atribuído conforme os ditames da lei, ainda que perversa. 
Assim como em outras situações de mudanças significativas na legislação, a extinção do "passe" não foi imediata. Para que os clubes de futebol profissional se adequassem a nova legislação e minimizassem possíveis prejuízos com a extinção do "passe", foi concedido um prazo. A Lei Pelé (1998) previa, a partir de sua publicação, o período de três anos para que todos os direitos anteriores denominados "passes" deixassem de existir. Então, de fato, a extinção do "passe" somente ocorreu a partir de março de 2001. Por fim, nesse contexto, para orientar os clubes de futebol profissional em situações futuras, com rupturas unilaterais de contratos por parte dos atletas decorrentes da extinção do "passe", foi instituído mecanismos de indenizações (de formação ou de promoção)

Sobre o contexto geral, argumenta Melo Filho (2001), ao mesmo tempo em que elidem os vícios e defeitos do extinto passe, é implementado um sistema mais sólido, realista e equitativo, harmonizando os direitos compensatórios dos clubes formadores com a liberdade dos atletas, conferindo maior segurança e estabilidade às relações desportivas e trabalhistas.

Os direitos econômicos derivam dos direitos federativos e, num contexto inovador, podem ser compartilhados entre vários agentes. Desta forma, os direitos econômicos podem ser exercidos pelos clubes ou por investidores, em frações ou no todo. O investidor em direitos econômicos (de atletas de futebol profissional) não difere, nos riscos que assume e objetivo de realização de lucro no futuro, daquele que investe em quaisquer outros tipos de ativos.

Como qualquer outro tipo de ativo, o investidor auferirá lucro, somente se houver valorização do atleta no "mercado da bola" e a efetiva concretização de uma transação, que em geral implica na transferência dos direitos federativos do atleta para outro clube. Os direitos econômicos, quando compartilhados, são fracionados entre os agentes econômicos, Ihes garantindo participação no valor da cláusula penal na hipótese de uma futura indenização pelos direitos federativos ao clube atual do jogador de futebol, antes do término do contrato. Por outro lado, os direitos econômicos são passíveis de serem objetos de transação entre os agentes, independente de negociações de direitos federativos por serem ativos econômicos. No entanto, não há regulação oficial e tampouco mecanismos de regulação pelos pares, há semelhança nas regras de governança, que assegure plena publicidade e transparência à esses negócios.

A formalização para o exercício dos direitos econômico, pelos clubes de futebol profissional, só é possível se forem firmados contratos civis, constando expressamente direito à partilha da cláusula penal existente entre o jogador de futebol e um clube (MELO FILHO, 2013). Em essência, significa que se um clube de futebol profissional decide negociar o direito federativo de determinado atleta, poderá fazê-lo em troca de um valor. Esse valor é relacionado ao direito econômico, portanto, é a compensação financeira recebida pelo clube para abrir mão dos seus direitos federativos com um atleta, liberando-o, para jogar por outro clube (GONÇALVES, 2012).

A atividade do atleta profissional é caracterizada por remuneração pactuada em contrato especial de trabalho desportivo, firmado com entidade de prática desportiva. Este contrato deverá conter duas espécies de multas indenizatórias que, se incorridas, resultam nos chamados direitos econômicos decorrentes de contratos entre clubes e atletas profissionais de futebol: a cláusula indenizatória desportiva (devida à entidade desportiva) e a cláusula compensatória desportiva (devida ao atleta profissional) (BRASIL, 1998).

Há um fundamento econômico, implícito, à semelhança de valuation de empresas, na determinação do valor da cláusula indenizatória desportiva, utilizando múltiplos do salário médio contratual do atleta profissional. Por isso, é beneficiária exclusiva da cláusula indenizatória desportiva, a entidade de prática desportiva à qual o atleta está vinculado, nas seguintes condições: (i) transferência do atleta para outra entidade, nacional ou estrangeira, durante a vigência do contrato especial de trabalho desportivo; ou (ii) por ocasião do retorno do atleta às atividades profissionais em outra entidade de prática desportiva, no prazo de até 30 (trinta) meses. O pagamento da cláusula indenizatória desportiva - devida a entidade esportiva cedente dos direitos federativos - é de 
responsabilidade do atleta profissional de futebol e da entidade desportiva contratante, de forma solidária.

Na situação de transferência do atleta profissional para clubes no território brasileiro, o valor da cláusula indenizatória desportiva é livremente pactuado entre o clube de futebol profissional e o atleta profissional, especificado em cláusula no contrato de prática desportiva firmado, limitado ao múltiplo de 2.000 (duas mil) vezes o valor médio do salário contratual. Para as transferências internacionais, não há limitação na fixação de valor da cláusula indenizatória, devida, inclusive, caso o atleta profissional de futebol, por meio de triangulação se transfira inicialmente para um clube no Brasil e, depois de três meses, para o exterior.

Por outro lado, o atleta profissional é beneficiário da Cláusula Compensatória Desportiva (BRASIL, 1998), por ocasião da dissolução do contrato desportivo com a entidade desportiva contratante. A dissolução pode ocorrer nas seguintes situações: (i) com o término da vigência do contrato ou o seu distrato; (ii) com o pagamento da cláusula indenizatória desportiva ou da cláusula compensatória desportiva; (iii) com a rescisão decorrente do inadimplemento salarial, de responsabilidade da entidade de prática desportiva empregadora, nos termos desta Lei; (iv) com a rescisão indireta, nas demais hipóteses previstas na legislação trabalhista; e (v) com a dispensa imotivada do atleta.

O valor da Cláusula Compensatória Desportiva é livremente pactuada entre o atleta profissional (beneficiário exclusivo) e a entidade esportiva contratante, limitado ao múltiplo de 400 (quatrocenta) vezes o valor do salário médio mensal na data da rescisão, como limite mínimo, e os valores remanescentes devidos até o término do contrato (BRASIL, 1998).

Além das multas estabelecidas nas cláusulas indenizatória desportiva e compensatória desportiva, a lei vigente prevê que sejam pagas indenizações ao clube formador de atletas profissionais de futebol, quando impossibilitado de firmar o primeiro contrato especial de trabalho desportivo. Como as relações entre atletas - quer em formação ou profissional - nem sempre são livres de tensões e/ou outros interesses de terceiros, que podem ocorrer (i) por oposição do atleta ou (ii) por ele se vincular, sob qualquer forma, a outra entidade de prática desportiva, sem autorização expressa da entidade de prática desportiva formadora. Dessa forma, o clube formador, amparado pela lei, é beneficiário de indenização (BRASIL, 1998).

\subsection{PRÁTICAS DE CAPTAÇÃO DE RECURSOS PELOS CLUBES DE FUTEBOL PROFISSIONAL BRASILEIROS.}

O futebol, enquanto negócio, tem uma capacidade de impulsionar outros tipos de negócios e, por outro lado, é refletido na composição e mix de suas receitas. Nesse contexto, Ekelund (1998) argumenta que a evolução do sistema de receitas é um bom indicador do consumo na indústria do futebol profissional: (i) Até a década de 1950 - A Era do Estádio: a relação entre o clube e o torcedor era o ponto central e ocorria no entorno dos estádios de futebol; (ii) Entre as décadas de 1950 - 1970 - A Era da TV Comercial Tradicional: fase em que as os jogos eram transmitidos gratuitamente pelas TV's, originando os patrocinadores; (iii) Década de 1980 - A Era dos Patrocinadores: época em que o interesse pela visibilidade proporcionada pela audiência alcançou os patrocinadores; e (iv) Após a década de 1980 - A era da Nova Mídia: o grande objetivo é o retorno financeiro. A televisão e a internet são os grandes consumidores intermediários. De um modo geral, os geradores de receitas, independente das eras, direta ou indiretamente são os consumidores do produto futebol.

Os consumidores de futebol são classificados por Leoncini (2001) em duas categorias: (i) consumidores finais e (ii) consumidores intermediários. Os torcedores estão na categoria de consumidores finais e as emissoras de TV, loterias e patrocinadores na categoria de consumidores intermediários. Os clubes consideram como mais importante o relacionamento com os consumidores finais, por determinarem o potencial de geração de recursos. 
A BDO RCS (2012) analisou as receitas dos 20 principais clubes de futebol profissional brasileiro. Apurou que o montante das receitas dos 20 clubes em 2011 foi de $R \$ 2,14$ bilhões representando um crescimento de $27 \%$ em relação a 2010 . As receitas dos clubes, em sua maior parte, é formada por cotas de TV, propaganda e publicidade, receitas com atletas, futebol amador e bilheterias. O Gráfico 1 detalha a composição das receitas consolidadas por ano.

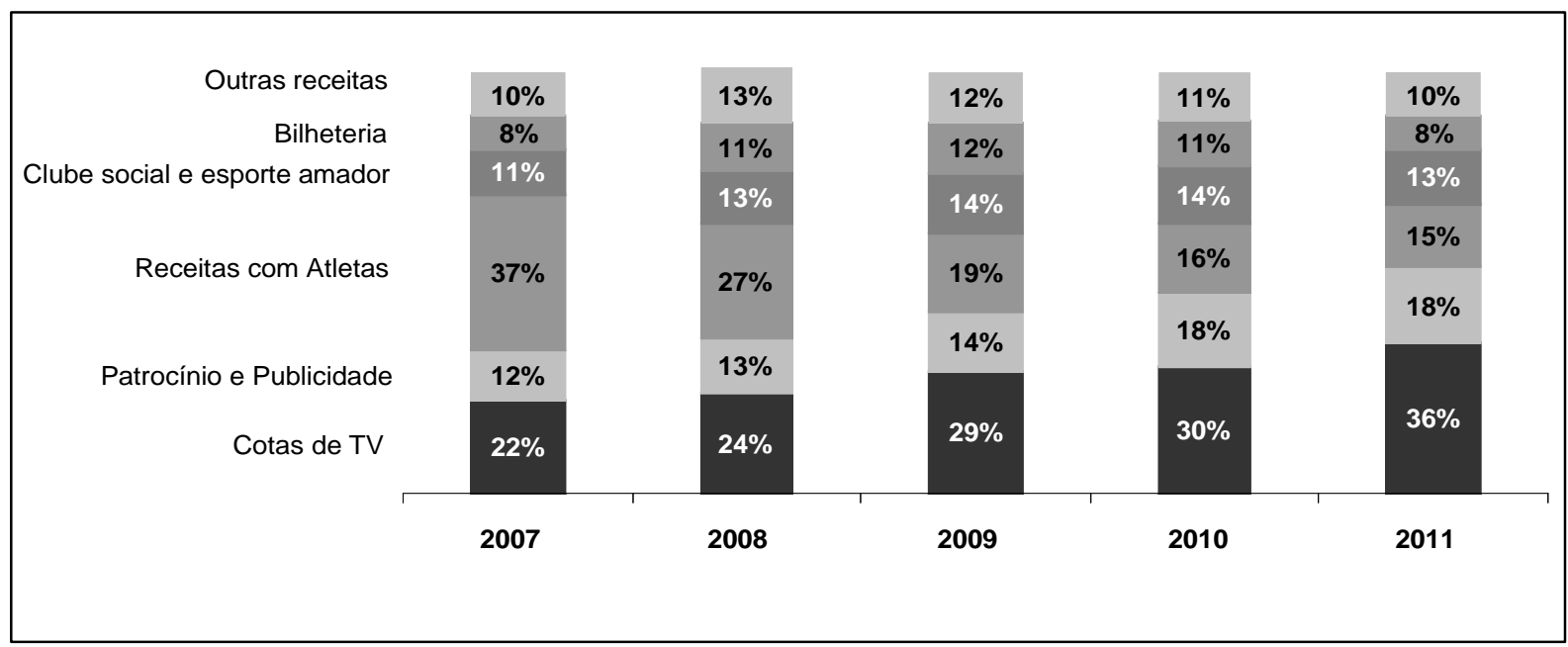

Gráfico 1: Distribuição das Receitas nos 20 Maiores Clubes Fonte: BDO RCS (2012).

Analisando o Gráfico 1, constatamos que: (i) gradativamente, as receitas com cotas de TV, as receitas com patrocínio e publicidade, respondem pelo maior volume na geração de recursos; (ii) as receitas de bilheterias, apesar do "respiro" em 2009, são pouco expressivas; e (iii) declínio das receitas com transferências de atletas, que em 2007 representavam 37\% das receitas totais, em 2011 participam com apenas $15 \%$.

No período analisado, as receitas com transferências de atletas, gradativamente perdem participação no mix de receitas, obviamente, impactam as finanças dos clubes. Um ponto a ser analisado e a correlação dessa redução de receita com o fim a lei do "passe", uma vez que, atualmente, o direito econômico de jogadores talentosos e valorizados é fracionado entre vários investidores.

É notória a dependência financeira cada vez maior dos clubes de futebol profissional das receitas de cotas televisivas, implicando em subordinação aos interesses das emissoras. O modelo de negócio dos clubes, com dependência das emissoras de TV, tem sido contestado até pelos atletas. Organizados em um grupo denominado "Bom Senso Futebol Clube", os atletas tem promovido protestos, inclusive contra o excessivo número de partidas (O ESTADO DE SÃO PAULO, 2013), atraindo a atenção da mídia nacional e internacional.

\subsection{MERCADO DE AÇÕES BRASILEIRO: CARACTERÍSTICAS E ABERTURA DE CAPITAL}

Assaf Neto (2009) argumenta que uma empresa somente cria valor se o retorno do capital investido em sua atividade exceder o custo de oportunidade das suas fontes de financiamento. Portanto, quando toma decisões de investimento com este diferencial, aumenta o seu valor agregado, e passa a ser (a empresa) uma atraente oportunidade para aplicação de recursos.

As empresas desenvolvem suas atividades em ambiente de crescente competitividade e competição por clientes e recursos. Para gestão dos negócios e expansão de suas atividades, as empresas, nesse ambiente, se deparam com uma crescente necessidade de recursos financeiros. Argumentam Cavalcanti e Misumi (2002, p. 147), que em tal contexto, a administração deve obter o máximo de 
lucros com o mínimo de investimentos, que podem ser de três fontes: (i) Financiamentos de Curto Prazo, com vencimentos inferior a 360 dias; (ii) Financiamentos de Longo Prazo, com vencimentos superiores a 360 dias, e (iii) Capital Próprio, sem prazo definido para vencimento ou resgate.

As fontes de financiamentos são diversificadas quanto à origem e tipos de recursos. Algumas fontes de financiamento são originadas espontaneamente das operações usuais: fornecedores privados e públicos de materiais e serviços, salários, tributos financiados pelo governo, dentre outros. As fontes de financiamentos consideradas como não espontâneas, são, em geral, empréstimos com instituições financeiras (CAVALCANTI; MISUMI, 2002, p. 148). Os investimentos financeiros usualmente são classificados em monetários e não-monetários. Os investimentos na categoria de monetários são representados pelo dinheiro em circulação no país acrescido dos recursos depositados - a vista - em instituições financeiras. Integram a categoria de investimento não monetários os títulos e valores mobiliários negociados no mercado (debêntures, ações, letras de câmbio, certificados de depósito, etc.) (ASSAF NETO, 2009).

Uma organização pode ter recursos obtidos de duas fontes distintas. A primeira fonte é formada por fornecedores de recursos - quer espontâneos ou não espontâneos - externo a empresa, chamado de Recursos de Terceiros. A segunda fonte, de Recursos Internos. Ambos os tipos estão diagramados na Figura 2.

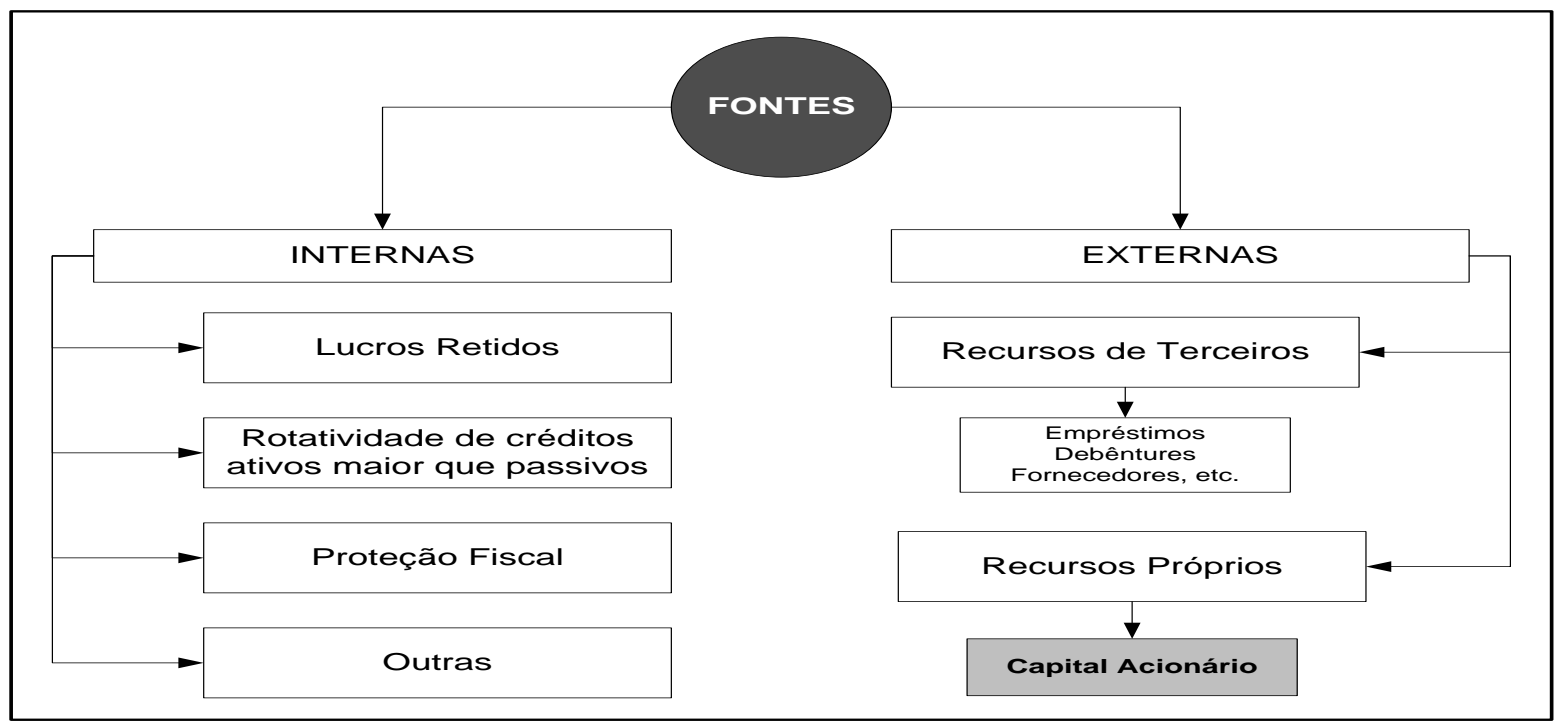

Figura 2: Fontes de Recursos para Financiamento Empresarial.

Fonte: Adaptado de Cavalcanti e Misumi (2002, p. 148)

A correta decisão para a definição da fonte dos investimentos é de extrema importância e pode ser a diferença entre o sucesso e o fracasso da atividade que se propõe a executar, uma vez que cada uma destas fontes apresenta características específicas, bem como custos diferenciados. Esta investigação aborda a captação de recursos no mercado acionário, um tipo específico de fonte externa de recursos. No mercado acionário, vários fatores impulsionam a abertura de capital nas empresas e na visão de Trevisan (2005) estão resumidos na Figura 3. 


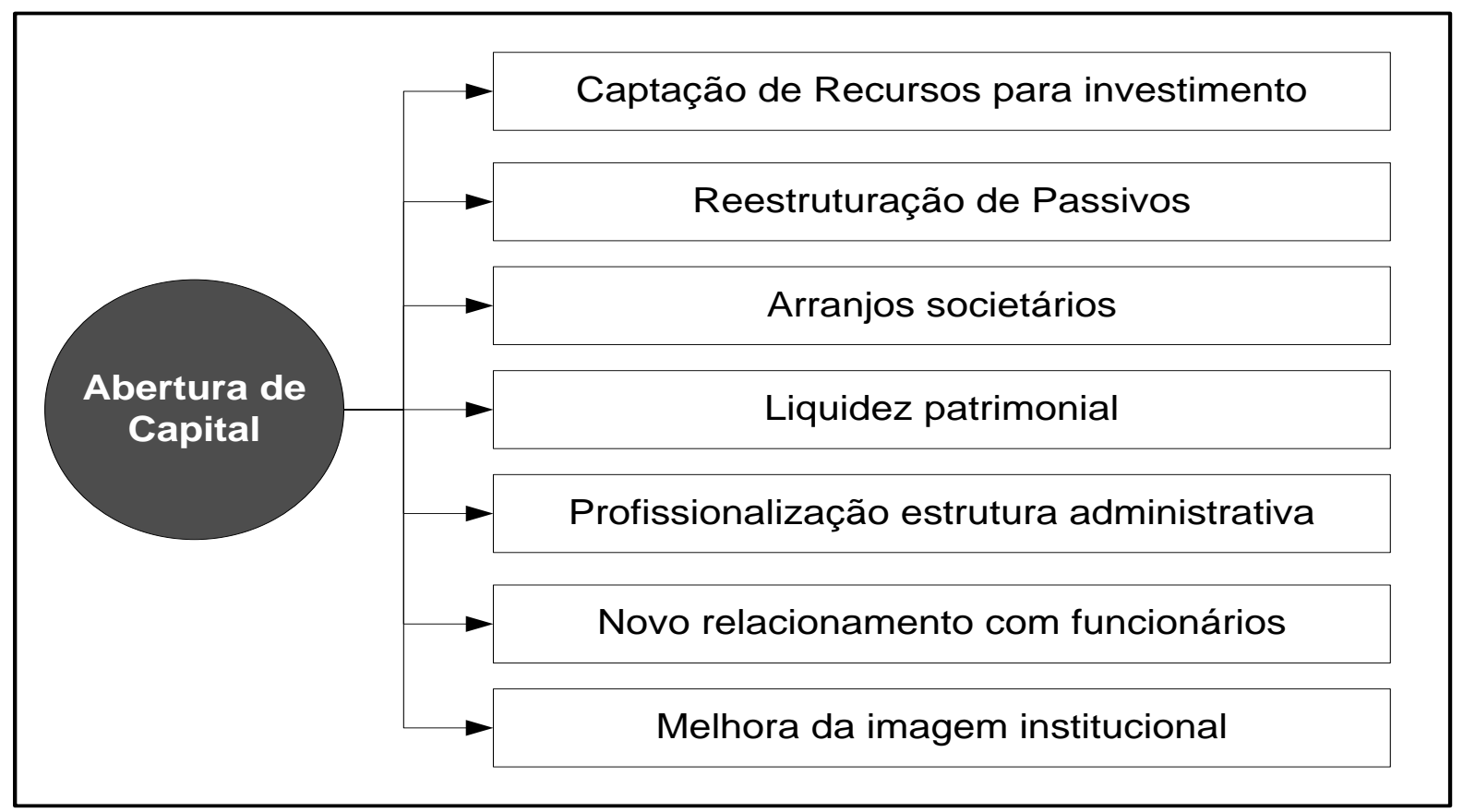

Figura 3: Motivos para a Abertura de Capital

Fonte: Adaptado de Trevisan (2005).

Para negociar suas ações no mercado acionário, a empresa deve aderir às regras do Sistema Financeiro Nacional (SFN). O SFN, formado por um conjunto de instituições e instrumentos financeiros e, operacionaliza a transferência de recursos entre ofertadores e tomadores, proporcionando a liquidez necessária no mercado. O sistema financeiro compreende os subsistemas: (i) Normativo (normas legais) que regula e controla o operativo; e (ii) Operativo, composto por instituições financeiras públicas e privadas que atuam no mercado (CAVALCANTE; MISUMI; RUDGE, 2009, p. 35-38).

Fato marcante para o mercado acionário brasileiro é a estruturação legal das sociedades anônimas, Lei no 6.404/76. A referida legislação, entre as várias definições, definiu que o capital de uma empresa sociedade anônima é dividido em ações e a responsabilidade dos acionistas limitada ao preço de emissão das ações subscritas ou adquiridas. As ações, de acordo com Assaf Neto (2009, p. 167), são títulos representativos da menor fração do capital social de uma sociedade anônima. O acionista, detentor da ação, não é credor da sociedade e na condição de coproprietário da sociedade tem direitos assegurados na participação dos resultados.

Cavalcanti, Misumi e Rudge (2009, p. 110), sintetizam as principais características das ações em cinco pontos: (i) considerada contabilmente como um crédito não exigível do acionista; (ii) sem prazo estabelecido de resgate; (iii) constitui-se em instrumento para obter recursos financeiros para financiamento das atividades da sociedade; (iv) pode ser representada materialmente por um certificado (cautela); e ( $v$ ) atualmente representada no formato escritural, como item em extrato da corretora.

Nos termos da Lei no 6.404/76, as ações são classificadas em dois grupos: (ii) Ordinárias, asseguram aos proprietários o direito a voto nas assembleias da sociedade; e (ii) Preferenciais, por outro lado, garantem a prioridade aos seus proprietários no recebimento de dividendos da sociedade e reembolso do capital investido. Ambas as categorias de ações - ordinárias e preferenciais - podem ser emitidas em classes, conforme estabelecidas no estatuto da sociedade.

Vários são as exigências e requisitos para uma empresa comercializar ações no mercado, por meio da Bolsa de Valores. Inicialmente, a empresa, deve estar registrada como sociedade de capital aberto, 
ou companhia aberta na Comissão de Valores Mobiliários (CVM). O lançamento público de ações novas no mercado é conhecido pelo nome de Underwriting. Resumidamente, este processo ocorre quando a sociedade, intermediada por um agente financeiro, emite e disponibiliza suas ações no mercado primário, captando os recursos necessários ao financiamento de suas atividades operacionais. Quando o detentor das ações resolve vende-las a terceiros, também, com a participação de agente financeiro, diz-se que ocorreu uma distribuição secundária, caracterizada pela ausência de entrada de recursos na sociedade (ASSAF NETO, 2009, p. 178).

A captação de recursos por meio de lançamento de ações no mercado acionário é uma alternativa as empresas. No Brasil, o marco regulatório do mercado de ações permite que somente as empresas constituídas como sociedade anônimas participem deste mercado. O locus no Brasil para emissão de ações, captação e listagem é a BM\&FBovespa. Dessa forma, os clubes de futebol profissional brasileiros, em sua maioria constituídos na forma de associação civil sem fins lucrativo, estão, por lei, excluídos de participar do mercado acionário e, por consequência, de captar recursos para financiar o seu negócio.

\section{METODOLOGIA}

Esta investigação é caracterizada como descritiva e seu foco é observar, registrar, analisar e correlacionar fatos ou fenômenos sem a manipulação dos mesmos. Nesta abordagem, o objetivo é descobrir, com precisão possível, a frequência com que um fenômeno ocorre, sua relação e conexão com outros, suas características e natureza (CERVO; BERVIAN, 1983). Com similar entendimento, Sampieri, Collado e Lucio (2006) apontam o estudo descritivo como aquele que visa medir, avaliar e coletar dados sobre vários aspectos do fenômeno em análise, de modo que suas propriedades consideradas importantes sejam especificadas.

A pesquisa é orientada pela estratégia Estudo de Caso. Para levar a cabo a estratégia de pesquisa adotada, alguns elementos são essenciais para sua condução: (i) exposição do problema de pesquisa e base bibliográfica que formam a teoria preliminar que está sendo avaliada; embasamento teórico e legal; (ii) apresentação do planejamento da pesquisa, com destaque para a elaboração do protocolo do caso contemplando a descrição dos instrumentos de obtenção de informações e evidências; (iii) as estratégias para a coleta e análise dos dados; (iv) as necessárias triangulações dos dados e informações obtidos; ( $v$ ) o encadeamento de evidências e avaliações para a explicação do objeto de estudo que consiste no caso propriamente dito (MARTINS, 2006).

Para Yin (2005), o estudo de caso é um modo de se investigar um tópico empírico seguindo um conjunto de procedimentos pré-especificados. Ainda, conforme o autor, o estudo de caso pode ser utilizado com a finalidade de explicar os vínculos causais em intervenções da vida real, descrever uma intervenção e o contexto da vida real em que ocorreu, ilustrar determinados tópicos dentro de uma avaliação, explorar situações nas quais a intervenção que está sendo avaliada não apresenta um conjunto simples e claro de resultados e, também, ser empregado para fazer um estudo de avaliação.

A organização, objeto de investigação, é o Paraná Clube. A escolha intencional origina-se no fato de que este clube de futebol, de maneira inédita no Brasil, efetuou operação de integralização de capital social numa sociedade anônima de capital aberto, utilizando os ativos representados pelos direitos econômicos decorrentes dos contratos mantidos com atletas profissionais de futebol. Esta operação assume maior importância quando considerado o fato de que, ao contrário de outros países (europeus, principalmente), no Brasil não é permitida a abertura de capital de entidades desportivas constituídas na forma de associação civil sem fins lucrativos. Aliás, não há notícia sequer de operação similar à ocorrida. 
No contexto do tema investigado, com relação a dimensão de tempo, é classificada como transversal retrospectiva. Duas fontes de dados serão utilizadas, a saber: a primeira, dados secundários que compreendem as Demonstrações Contábeis, Atas de Assembleias e demais documentos referentes ao período de 2012 e 2013; e, a segunda, dados primários que foram coletados por meio de entrevistas abertas e semiestruturadas com diretores, contadores e outros profissionais do Paraná Clube e Atletas Brasileiros S/A, envolvidos no processo de abertura indireta de capital.

\section{RESULTADOS E DISCUSSÃO}

\subsection{DESCRIÇÃO DAS ENTIDADES ENVOLVIDAS}

\subsubsection{Paraná Clube}

O Paraná Clube foi fundado em 19 de dezembro de 1989, na forma de associação civil sem fins lucrativos, com duração indeterminada, pela fusão do Colorado Esporte Clube e do Esporte Clube Pinheiros. Na ocasião, a fundação de um clube de futebol a partir da fusão de dois outros, trouxe para o negócio futebol conceitos similares aos utilizados no meio empresarial: as fusões que unem ex-concorrentes para, juntos, conquistarem ainda mais mercado. (PARANA CLUBE, 2013).

A sede administrativa e social do clube, na cidade de Curitiba-PR é na Avenida Presidente Kennedy, 2377, Vila Guaíra. A estrutura desportiva do Paraná Clube é composto pelos estádios Durival Britto e Silva (Vila Capanema) e Erton Coelho Queiróz (Vila Olímpica) e um centro de treinamento. No cenário desportivo paranaense e brasileiro, o Paraná Clube apresenta o seguinte desempenho: Campeão Brasileiro da Segunda Divisão em 1992 e em 2000 (Copa João Havelange - Módulo Amarelo) e Campeão Paranaense em 1991, 1993, 1994, 1995, 1996, 1997 e 2006 (PARANÁ CLUBE, 2013).

No ranking da Confederação Brasileira de Futebol (CBF) 2013, entre os 229 clubes de futebol brasileiros filiados à CBF em 2013, o Paraná Clube estava na 27ạ posição, com 5.924 pontos. Essa posição, de acordo com critério de graduação pré-estabelecida pela $\mathrm{CBF}$, considera o desempenho desportivo do clube até o ano de 2012 (CBF, 2013).

\subsubsection{ATLETAS Brasileiros S/A}

A empresa Atletas Brasileiros S/A foi fundada em 07 de junho de 2010, obteve o Número de Identificação do Registro de Empresas (NIRE), emitido pela Junta Comercial em 30/06/2010 e registro no Cadastro Nacional das Pessoas Jurídicas (CNPJ) sob $n^{\circ}$. 12.610.165/0001-64. Inicialmente, a empresa foi concebida como veículo de investimento em fase pré-operacional com a finalidade de obtenção do registro como sociedade anônima de capital aberto, na CVM e listagem na BM\&FBOVESPA S.A - Bolsa de Valores, Mercadorias e Futuros. Dessa forma, estava atendendo os requisitos para atuar posteriormente, na fase operacional, captando recursos por meio de lançamento de ações.

O objeto social da empresa, formado por um conjunto de atividades direcionadoras de seus negócios é detalhado no Quadro 2.

Quadro 2: Objeto Social da Atletas Brasileiros S/A

\begin{tabular}{|c|l|}
\hline ITENS & \multicolumn{1}{|c|}{ OBJETO SOCIAL } \\
\hline $\mathbf{1}$ & Compra e venda de direitos econômicos de jogadores de futebol; \\
\hline $\mathbf{2}$ & Organização e administração de investimentos de terceiros em ativos futebolísticos; \\
\hline $\mathbf{3}$ & Representação de atletas em associação com agentes credenciados pela FIFA; \\
\hline $\mathbf{4}$ & Administração de carreiras de jogadores de futebol e outros atletas brasileiros; \\
\hline $\mathbf{5}$ & Administração de centros de treinamento; \\
\hline $\mathbf{6}$ & Criação e/ou administração de clubes de futebol. \\
\hline
\end{tabular}

Fonte: Adaptado do Estatuto Social da Atletas Brasileiros S/A 
Conforme detalhado no Quadro 2, os interesses de atuação da Atletas Brasileiros S/A no negócio esportes são amplos, porém, como foco principal concentra sua atenção na gestão do futebol. Esse aspecto - gestão do futebol - é o ponto de sustentação do modelo de negócio da Atletas Brasileiros S/A e respectivo plano de negócios, portanto, direcionando os esforços apenas e tão somente ao segmento dominado pela gestão.

\subsection{A ESTRATÉGIA DE CAPTAÇÃO DE RECURSOS NO MERCADO DE AÇÕES: ABERTURA INDIRETA DE CAPITAL}

\subsubsection{Breve análise das Receitas nos Clubes De Futebol PROFISSIONAL BRASILEIRO}

O futebol, como qualquer segmento econômico, demanda recursos para financiar suas atividades. A correta decisão para a definição da fonte dos investimentos, além de estratégico, em geral é a diferença entre o sucesso e o fracasso do empreendimento. Deve ser considerado, que cada fonte de recursos tem, além de características específicas decorrentes dos tipos de agentes envolvidos, prazos e custos diferenciados.

Em países com mercado de ações desenvolvido, uma das opções geralmente utilizadas no mundo corporativo é a captação de recursos com ofertas de ações, quer inicial ou não. A estratégia de captação de recursos mediante abertura de capital na Bolsa de Valores tem sido utilizada por número cada vez maior de empresas no Brasil e no mundo. Especificamente no Brasil, a Deloitte (2013) pondera que, apesar do declínio de número de ofertas iniciais em 2008 e 2009, reflexos da crise nos Estados Unidos, ainda assim, é verificado um crescente aumento no número de lançamentos ao longo dos anos.

A abertura de capital, na avaliação de Trevisan (2005), é um dentre outros meios disponíveis para captar recursos e financiar as atividades. Na Europa, os clubes de futebol são constituídos como empresas e muitos captam recursos no mercado acionário. Os clubes de futebol profissional brasileiros, por força do marco regulatório vigente, são impedidos de abrirem seu capital, de ofertarem ações por meio de IPO e, assim, financiarem suas atividades. Os montantes de recursos financeiros captados pelos clubes de futebol profissional brasileiro, pelos meios usuais, considerando todas as formas de origem dos recursos, sequer se aproximam dos valores movimentados pelos clubes europeus com ações listadas nas Bolsas de Valores. As diferenças são abissais.

Pelas características dos clubes de futebol profissional, fundamental no negócio desportivo e ponto sensível como fonte de receitas, são as transações comerciais com os direitos econômicos dos atletas profissionais. Uma análise crítica do mix de receitas dos clubes requer considerar a participação das receitas com vendas de atleta e seu comportamento ao longo de um horizonte temporal.

O levantamento efetuado pela BDO RCS (2012) sobre as fontes de receitas dos 20 maiores clubes de futebol brasileiros evidencia, no horizonte temporal analisado, o declínio das receitas com a comercialização de direitos econômicos sobre atletas profissionais. Dessa forma, é latente a redução da participação das receitas de comercialização de direitos econômicos na composição da receita total.

A BDO RCS (2012) destaca que, referente aos 20 maiores clubes de futebol profissional brasileiro, as receitas com direitos econômicos sobre atletas profissionais representavam 37\%, 27\%, 19\%, 16\% e $15 \%$ das receitas, respectivamente, para os anos de 2007, 2008, 2009, 2010 e 2011 . Os demais tipos de receitas - bilheteria, clube social, publicidade, cotas de TV e outras - detalhadas no levantamento não são objetos de nossa análise. 


\subsection{2 estratégia de Captação de Recursos no Mercado ACIONÁRIO NO BRASIL: ABERTURA INDIRETA DE CAPITAL}

\section{O CONTEXTO}

No modelo atual, a captação de recursos pelos clubes de futebol profissional está centrada em dois direcionadores geradores de receitas: (i) performance técnica nos campeonatos e (ii) formação de atletas. A performance técnica nos campeonatos é um ponto chave na negociação do valor das cotas de TV e frequência de transmissões ao vivo que, por sua vez, é direcionador chave na geração de receitas de propaganda. Os atletas formados nas chamadas categorias de base, com elevado potencial e perspectivas de futuro, em geral, são objetos de transações comerciais, assegurando receitas sobre os direitos econômicos.

No atual ambiente, dois fatores críticos devem ser considerados no planejamento de um clube de futebol profissional: (i) a necessidade de recursos acessíveis para financiamento das atividades operacionais e (ii) o decréscimo constante da participação das receitas com comercialização de direitos econômicos nas receitas totais dos clubes de futebol brasileiros.

Por suas características de resultados no médio e longo prazo, a captação de recursos na bolsa de valores é a estratégia ideal para financiar as atividades nos clubes de futebol. No entanto, para os clubes de futebol profissional brasileiro, o marco legal estabelecido não permite de forma direta o acesso ao mercado acionário, mesmo porque, a maioria dos clubes estão formatados juridicamente como "organizações sem fins lucrativos".

Uma estratégia promissora, para contornar as imposições restritivas da lei, é, por meio de participação majoritária em uma empresa, constituída especificamente para tal fim. Esse tipo de arranjo é possível, tanto quanto negócio como nos aspectos legais, graças à dicotomia direito federativo e direito econômico decorrentes de contratos entre clubes e jogadores de futebol profissional. A empresa terá acesso a recursos por meio do lançamento inicial de ações - IPO - o que proporcionará o incremento das operações e aquisição de direitos econômicos, resultando em transações com os recursos (lucros) que serão repassados ao clube (acionista majoritário no caso do arranjo do Paraná Clube) como dividendos. Outras formas poderão ser pensadas.

Dessa forma, estará ocorrendo "a abertura indireta de capital" e essa estratégia pode ser considerada uma alternativa viável para atendimento dos dois fatores críticos mencionados: (i) acesso a recursos do mercado de ações e (ii) a implementação de política agressiva, profissionalizada e organizada de gestão dos direitos econômicos decorrentes de contratos mantidos com atletas profissionais de futebol.

\section{O Processo De ABERTURA INDIRETA DE CAPITAL}

Considerando os fatores e variáveis mencionados, em 2013, o Paraná Club orientado pela estratégia de "abertura indireta de capital", inicialmente, adquiriu participação na empresa Atletas Brasileiros S/A. A integralização do capital foi por meio da cessão dos direitos econômicos de contratos com atletas profissionais de futebol, na ocasião pertencentes ao clube.

A compreensão necessária para descrever o processo de "abertura indireta de capital", exigiu dos pesquisadores análise documental (atas, publicações, demonstrações financeiras, notícias, etc.), realização de entrevistas com os gestores do Paraná Club e do Atletas Brasileiros S/A, bem como, o exame de outras fontes disponíveis e, por fim, realizou-se o cruzamento dos dados. Findo essa fase, foi possível elaborar a Figura 4, que diagrama as etapas para operacionalizar e concretizar a estratégia de abertura indireta de capital. 


\begin{tabular}{|c|c|c|c|}
\hline ETAPAS & ATORES & EVENTOS & CONSEQUENCIAS \\
\hline 1 & Paraná Clube & $\begin{array}{c}\text { Avaliação prévia pela } \\
\text { Diretoria dos benefícios e } \\
\text { riscos esperados com a } \\
\text { operação de abertura } \\
\text { indireta. }\end{array}$ & $\begin{array}{c}\text { Diretoria decide pela abertura } \\
\text { indireta de capital, devendo o } \\
\text { assunto ser submetido aos } \\
\text { órgãos internos do Paraná } \\
\text { Clube. }\end{array}$ \\
\hline 2 & Paraná Clube & $\begin{array}{l}\text { Discussão e submissão } \\
\text { aos órgão internos. }\end{array}$ & $\begin{array}{l}\text { Aprovação do projeto pelo } \\
\text { Conselho Normativo, Conselho } \\
\text { Fiscal e Conselho Deliberativo. }\end{array}$ \\
\hline 3 & $\begin{array}{c}\text { Paraná Clube } \\
\text { Atletas Brasileiros }\end{array}$ & $\begin{array}{l}\text { Formatação e assinatura } \\
\text { de Memorando de } \\
\text { Entendimento. }\end{array}$ & $\begin{array}{l}\text { Ficam ajustadas as condições, } \\
\text { datas e valores para a operação } \\
\text { de integralização de capital. }\end{array}$ \\
\hline 4 & $\begin{array}{c}\text { Paraná Clube } \\
\text { Atletas Brasileiros }\end{array}$ & $\begin{array}{c}\text { Paraná Clube efetua a } \\
\text { venda dos direitos } \\
\text { econômicos à Atletas } \\
\text { Brasileiros. Paraná Clube } \\
\text { subscreve } 66,67 \% \text { do } \\
\text { capital da Atletas. } \\
\text { Ocorre a quitação da } \\
\text { venda e da integralização } \\
\text { de capital }\end{array}$ & $\begin{array}{c}\text { Paraná Clube remanesce como } \\
\text { acionista controlador da Atletas } \\
\text { Brasileiros S/A }(66,67 \%) \text {. } \\
\text { Atletas Brasileiros S/A } \\
\text { remanesce como detentora dos } \\
\text { direitos econômicos de } 59 \\
\text { atletas profissionais de futebol. }\end{array}$ \\
\hline 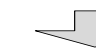 & $\sqrt{ }$ & $\sqrt{2}$ & $\sqrt{2}$ \\
\hline \multicolumn{4}{|c|}{ ABERTURA INDIRETA DE CAPITAL } \\
\hline
\end{tabular}

Figura 4: Resumo do Processo de Abertura Indireta de Capital Fonte: Elaborado com base nos documentos analisados.

As etapas descritas resultaram em participação acionária do Paraná Clube na Atletas Brasileiros S/A. Os direitos econômicos dos jogadores, por força da integralização de capital, foram cedidos à Atletas Brasileiros S/A. Como consequência dos eventos administrativos e jurídicos ocorridos, os direitos econômicos decorrentes de contratos mantidos entre jogadores profissionais de futebol e o clube, encontram-se registrados como ativos numa sociedade anônima de capital aberto, aptos a serem negociados com a esperada geração de resultados positivos.

$\mathrm{O}$ objetivo da Atletas Brasileiros S/A, quando finalizado o trâmite junto à CVM, é comercializar suas ações na BM\&FBovespa sob o código "BOLA3". O modelo de negócio inovador traz desafios para a gestão do Paraná Clube. Além de gerir o negócio futebol no formato tradicional, há também a empresa na qual o clube é acionista majoritário. No entanto, diante do atual modelo de negócios do futebol brasileiro e do marco regulatório, é uma promissora alternativa, viável, que em breve estará sendo testada de forma mais incisiva com a listagem das ações "BOLA3" na BM\&FBovespa, prevista para o primeiro semestre do ano de 2014.

Enquanto modelo de negócio, a estratégia de captação de recursos para financiar as atividades de um clube de futebol, com a "abertura indireta de capital", é evento inédito no mercado de ações brasileiro. Por fim, há a possibilidade de outros clubes serem acionistas da Atletas Brasileiros S/A.

\section{CONSIDERAÇÕES FINAIS}

Desde o final do século XIX, quando o futebol no Brasil começou a ser praticado no formato hoje conhecido, várias foram as fases experimentadas. Desde partidas totalmente amadoras praticadas por operários ingleses mesclados com brasileiros, passando pela profissionalização, formação de grandes clubes, paixões e construção de estádios monumentais. As Copas do Mundo, os 
campeonatos competitivos, nos dias atuais, são megaeventos, com faturamento bilionário, revelando o poderio econômico (e mesmo político) do desporto profissional denominado futebol. $\mathrm{Na}$ economia dos países, pela sua interação com os segmentos econômicos, assume de forma crescente um papel significativo na formação da riqueza nacional.

O desenvolvimento do negócio futebol é desigual no mundo, em especial, no aspecto econômico. No Brasil, a fronteira a ser cruzada é o ingresso do negócio futebol no mercado de ações. Uma entrada oficial, legal e revestida de todas as exigências impostas pelos necessários e rigorosos mecanismos de controle.

Esta última fronteira a ser vencida pode ser um dos mecanismos, senão o mais importante, para reintegrar ao Brasil a liderança no futebol mundial em todos os aspectos, notadamente, o econômico. Como sabido, os clubes de futebol brasileiros sequer se aproximam de seus pares europeus quando analisamos a participação no mercado de ações e, consequentemente, na possibilidade de captação de recursos a condições favoráveis.

Na Europa, as condições favoráveis na captação de recursos pelos clubes europeus, aliados a outros fatores locais, os remetem a serem protagonistas nas competições em que participam, originando um círculo vicioso: (a) mais recursos $\rightarrow$ (b) contrata melhores jogadores $\rightarrow$ (c) tem sucesso nas competições $\rightarrow$ (d) maior número de torcedores $\rightarrow$ (a) possui mais recursos ... (d) maior número de torcedores e, assim, sucessivamente.

O processo de abertura indireta de capital experimentado pelo Paraná Clube, com participação acionária relevante na Atletas Brasileiros S/A, é recente, esta na fase final dos trâmites burocráticos e, no momento, não há elementos para avaliar resultados. Poderemos nos deparar com estrondoso sucesso na oferta de ações, à semelhança e lastreado pelo crescimento do mercado de ações nos últimos anos (DELOITTE, 2013) ou, então, em caminho oposto e não desejado, onde os ativos não alcancem a valorização esperada, com reflexo negativo na valorização das ações, conforme projetado, e os resultados sejam, por fim, sinalizadores de que o processo de abertura indireta de capital, por um clube de futebol brasileiro, foi vencido pela letargia que move os fracassos de mercado.

Por ouro lado, a iniciativa é inédita, o desenho do negócio é inovador e legal quanto ao arcabouço jurídico. Neste contexto, a expectativa pelos bons resultados no gerenciamento dos direitos econômicos decorrentes de contratos com atletas profissionais de futebol é a melhor possível.

Por si só, o futebol, enquanto atividade econômica relevante no contexto da economia brasileira, ainda é carente de estudos aprofundados em seu gerenciamento. Como sugestão para futuros trabalhos, além do assunto futebol em geral, remanescem alguns bastante interessantes, tais como: (i) o comportamento dos preços das ações de uma empresa com ativos originados no futebol; (ii) a correlação dos resultados em competições e os preços das ações de uma empresa com ativos originados no futebol; e (iii) comparação do arcabouço legal incidente sobre clubes europeus e brasileiros.

\section{REFERÊNCIAS}

ASSAF NETO, A. Mercado financeiro. 9 ed. São Paulo: Atlas, 2009.

BDO RCS AUDITORES INDEPENDENTES. Finanças dos clubes brasileiros e o valor das marcas. Edição 2012. Disponível em: <http://www.bdobrazil.com.br/pt/publicacoes.html>. Acesso em 14 nov. 2013.

BOENTE, D. R.; DANTAS, M. G. S. A eficiência financeira e esportiva dos maiores clubes de futebol Europeu utilizando a análise envoltória de dados. Revista de Contabilidade e Organizações, v. 5 n. 13, p. 75-90, 2011. 
BRASIL. Decreto-Lei no 3.199, de 14 de abril de 1941. Estabelece as bases de organização dos desportos em todo o país. Diário Oficial da República Federativa do Brasil. Disponível em: <http://legis.senado.gov.br/legislacao/ListaPublicacoes.action?id=152593> Acesso em: 10 jul. 2013.

BRASIL. Lei no 6.354, de 2 de setembro de 1976. Dispõe sobre as relações de trabalho do atleta profissional de futebol e dá outras providências. Diário Oficial da República Federativa do Brasil. Disponível em: <http://www.planalto.gov.br/ccivil_03/leis/l6354.htm>. Acesso em: 10 jul. 2013.

BRASIL. Lei Federal n. 6.404, de 15 de dezembro de 1976. Dispõe sobre as Sociedades por Ações. Diário Oficial da República Federativa do Brasil. Disponível em: < http://www.planalto.gov.br/ccivil _03 /leis/l6404compilada.htm> . Acesso em: 10 fev. 2012.

BRASIL. Lei no 8.672, de 06 de julho de 1993 (Lei Zico). Institui normas gerais sobre desportos e dá outras providências. Oficial da República Federativa do Brasil. Disponível em: <http://www.planalto.gov.br/ccivil_03/leis/l8672.htm>. Acesso em: 10 jul. 2013.

BRASIL. Lei Federal no 9.615, de 24 de março de 1998. Institui normas gerais sobre desporto e dá outras providências. Diário Oficial da República Federativa do Brasil. Disponível em: < http://www.planalto.gov.br/ccivil_03/leis/19615consol.htm>. Acesso em: 10 jul. 2013.

BRASIL. Lei no 12.395, de 16 de março de 2011. Altera as Leis n오 9.615, de 24 de março de 1998, que institui normas gerais sobre desporto, e 10.891, de 9 de julho de 2004, que institui a Bolsa-Atleta; cria os Programas Atleta Pódio e Cidade Esportiva; revoga a Lei no 6.354, de 2 de setembro de 1976; e dá outras providências. Diário Oficial da República Federativa do Brasil. Disponível em: < http://www.planalto.gov.br/ccivil_03/_ato2011-2014/2011/lei/l12395.htm>. Acesso em: 10 jul.2013.

CAVALCANTI, F; MISUMI, J. Y. Mercado de capitais. Rio de Janeiro: Campus, 2002.

CAVALCANTE, F; MISUMI, J. Y.; RUDGE, L. F. Mercado de capitais: o que é, como funciona. Rio de Janeiro: Elsevier, 2009.

CERVO, A. L.; BERVIAN, P. A. Metodologia científica. 3. ed. São Paulo: McGrawHill, 1983.

CONFEDERAÇÃO BRASILEIRA DE FUTEBOL - CBF. Ranking nacional de clubes - temporada 2013. Disponível em: <http://imagens.cbf.com.br/201212/28291933.pdf>. Acesso em: 09 nov. 2013.

COMISSÃO DE VALORES MOBILIÁRIOS-CVM. Abertura de Capital de Empresas. Disponível em <http://www.cvm.gov.br/port/public/publ/publ_200.asp>. Acesso em 03/09/2013.

COOPER, D.R.; SCHINDLER, P.S. Métodos de pesquisa em administração. 7 ed. São Paulo: Bookman, 2003.

DELOITTE. Annual review of football finance 2013 highlights. Disponível em: <http://www.deloitte.com/view/en_GB/uk/industries/sportsbusinessgroup/sports/football/annualreview-of-football-finance/>. Acesso em 09 set. 2013.

DELOITTE. Custos para a abertura de capital no brasil. Disponível em: <http://www.deloitte.com/assets/Dcom-Brazil/Local\%20Assets/Documents/Estudos\%20e\%20 pesquisas/Pesquisa_Custosparaaberturadecapital.pdf>. Acesso em: 12 nov. 2013

EKELUND, P. A Rentabilidade das associações de times de futebol: os exemplos das ligas de futebol da Itália e da Inglaterra. In.:.CONGRESSO INTERNACIONAL EAESP DE GESTÃO DE ESPORTES, 1, Fundação Getúlio Vargas, 1998. Anais...

FÉDÉRATION INTERNATIONALE DE FOOTBALL ASSOCIATION - FIFA. History. Disponível em <http:// www.fifa.com/classicfootball/history/the-game/origins.html>. Acesso em 10 jul 2013. 
GONÇALVES, E. Um pouco mais sobre direito federativo e direitos econômicos: o caso Montillo.

Globo Esporte. Olhar crônico esportivo. 11 de janeiro de 2012. Disponível em: <http://globoesporte.globo.com/platb/olharcronicoesportivo/2012/01/11/um-pouco-mais-sobredireito-federativo-e-direitos-economicos-o-caso-montillo/>. Acesso em: 13 nov. 2013.

GUERRA, L. B. Consectários da extinção do passe no futebol brasileiro. Jus Navigandi. Novembro de 2003. Disponível em: <http://jus.com.br/artigos/4434/consectarios-da-extincao-do-passe-no-futebol -brasileiro>. Acesso em: 12 nov. 2013.

LEONCINI, M. P. Entendendo o negócio futebol: um estudo sobre a transformação do modelo de gestão estratégica nos clubes de futebol. 2001. Tese (Doutorado em Engenharia), Escola Politécnica, Universidade de São Paulo, São Paulo.

LOPES, J. S. L. A vitória do futebol que incorporou a pelada. Revista USP, Dossiê Futebol, n. 22, nota 17, 1994.

MARTINS, G. A. Estudo de caso: uma estratégia de pesquisa. São Paulo: Atlas, 2006.

MELO FILHO, A. Direitos Federativos e econômicos no futebol - distorções e correções jusdesportivas. IOB. Disponível em <http://www.iob.com.br/bibliotecadigitalderevistas/bdr.dll/ RDD/1582/1e9b/1ef5/1ef6/1ef7?f=templates\&fn=altmain-nf.htm\&2.0>. Acesso em: 12 nov. 2013.

MELO FILHO, A. Novo regime jurídico do desporto: comentários à Lei 9.615 e suas alterações. Suplemento de atualização. Brasília: Brasília Jurídica, 2001. .

O ESTADO DE SÃO PAULO, Jogadores cruzam braços e fazem silêncio em protesto do Bom Senso FC. Esportes Futebol. 13 de novembro de 2013. Disponível em: <http://www.estadao.com.br/noticias/ esportes,jogadores-cruzam-bracos-e-fazem-silencio-em-protesto-do-bom-senso-fc,1096374,0.htm>. Acesso em: 20 nov. 2013.

PARANÁ CLUBE. História. Disponível em: <http://www.paranaclube.com.br/oclube.htm>. Acesso em: 09 nov. 2013.

SOUZA, F. P; D' ANGELO, C. F. O fim do passe e seu impacto sobre o desequilíbrio competitivo entre as equipes de futebol. Revista de Administração, São Paulo, v. 40, n. 3, p. 280-288, jul./set. 2005.

SAMPIERI, R. H.; COLLADO, C. F.; LUCIO, P. B. Metodologia de pesquisa. 3. ed, São Paulo: McGraw Hill, 2006.

TREVISAN, A. M. Como participar do mercado de capitais. São Paulo: Trevisan Editora Universitária, 2005.

TUBINO, M. J. G. 500 anos de legislação esportiva brasileira: do Brasil-Colônia ao início do século XXI. Rio de Janeiro: Shape, 2002.

YIN, R. K. Estudo de caso: planejamento e métodos. 3. ed. Porto Alegre: Bookman, 2005. 